\title{
Analysis of the development and application of passive building technology in Macau
}

\author{
Liang Zheng ${ }^{1, *}$, Junrui $\mathrm{Cao}^{1,2}$, and Yile Chen ${ }^{1}$ \\ ${ }^{1}$ Macau University of Science and Technology, Avenida Wai Long Taipa Macau, China \\ ${ }^{2}$ Industrial Design Institute, Zhao Qing University, Zhao Qing, China
}

\begin{abstract}
As the country continues to pay attention to the goal of carbon neutrality, a series of green building design methods, application technologies, and evaluation standards have emerged in the construction field. Among them, passive buildings are used as a technology that does not require mechanical devices for heating, ventilation, and heat dissipation. High attention from the industry. In this context, this article explores the development of passive construction in Macau, analyzes the application status of this technology in Macau, summarizes and puts forward the key points and feasibility recommendations of passive construction technology in Macau and areas with similar geographic climates. It is passive construction technology. Provide basis and basic data for the application and certification of related evaluation standards in Macau.
\end{abstract}

\section{Introduction}

The names of passive buildings vary significantly in different countries and regions due to different certification agencies and language environments. The Passive House Institute of the United States (PHIUS) calls it a passive house, emphasizing the comfort, air quality, resilience, and net zero of the building [1]; the German Passive House Institute (PHI) called it a passive house (Passivhaus), focusing on achieving energy-efficient, comfortable and affordable building standards [2]; the Swedish Energy-Efficient Building Forum (FEBY) called it a low-energy building (Minienergi), and proposed energy requirements It is variable depending on the climate zone, and it is necessary to calculate the precise heat load and energy demand to formulate the design strategy [3]; in Japan's regional open center, it is a house without heating, emphasizing that the energy used by the building is generated from the house [4]; In the construction standards of China's construction engineering industry promulgated in 2012, China called it passive solar buildings, focusing on the characteristics of buildings using solar energy for heating and heat dissipation [5]. The different names not only reflect the optimism of the building certification agency on the passive building certification market but also reflect the characteristics of passive buildings adapting to local conditions. With the differences in local climate characteristics, resource conditions, economic conditions, technical levels, functional use and folk customs, passive buildings. That technology has extended targeted technical methods and measures in site planning,

\footnotetext{
*Corresonding author: zlanger@163.com
} 
building size, space and envelope structure, heat collection and storage, ventilation and shading, and building institutions.

\section{The origin of passive architecture}

Architecture is an enclosed space for human beings to provide safety, comfort, and living in various harsh natural environments. Early humans did not have modern equipment such as air conditioners, water heaters, and dehumidifiers. Instead, they used the natural environment and physical effects to adapt the buildings to changes in natural climate, which can significantly reflect the early passive in traditional regional buildings in different countries and regions. Features of construction technology. In 100 BC, the ancient Rome Vitruvius' "Ten Books of Architecture" described the design principles of the relationship between architectural orientation and climate [6].

In 1932, the Royal Building Society formulated the "Building Orientation", which believed that good building orientation can improve the energy efficiency of houses and make the living environment more comfortable [7]. By calculating the solar angle throughout the year, considering the changes in the solar path between summer and winter, the need for heating and cooling is balanced between capturing sunlight and natural wind, and good building orientation is formulated to reduce the need for auxiliary heating and cooling.

In 1960, American Rainer Bannerm's "The Architecture of a Moderate Environment" proposed to treat technology, human needs, and environmental issues as components of architecture [8]. Summarize a large number of building materials that use solar energy, and give examples of traditional Indian architecture, Indian traditional architecture, solar architecture at that time, and the Pompidou National Art and Cultural Center, emphasizing the wisdom of traditional residential buildings in response to the environment.

In 1976, "People, Climate, and Architecture" by Givone in the United States considered that comfort is an important parameter of buildings and that thermal comfort is the main factor in achieving human comfort, and proposed that heat can be achieved in buildings even in harsh climates. The technical strategy of comfort [9].

In 1987, Cade and Brown published "Solar Radiation, Wind and Natural Light: Architectural Design Strategies", which was used as a classic design guide for passive buildings. They believed that buildings should be heated in the sun, cooled in the wind, and illuminated in the sky [10]. The book also proposes 7 building optimization methods, 9 passive building strategies, 6 building evaluation indicators, and 100 preliminary design strategies. It combines theory with engineering practice and promotes the development of modern passive buildings.

In 1992, Brown and a number of scholars in the United States published "The Design Process of Passive Environmental Technology", which gradually analyzed sites, buildings, buildings, regions, etc. from the perspective of culture to climate, through thermal, acoustic, optical, water and waste utilization Such knowledge applies passive architectural technology to spaces of different scales [11].

In 1994, Yang Jingwen, Malaysia, "Nature Design: Ecological Basis of Architectural Design", provided a complete technical system of passive architecture, comprehensively sorted out the impact of various architectural works on the natural environment, and emphasized the low energy consumption, ecological climate, and materials of buildings. Recycling, land use, resource management, and maintenance materials, etc., believe that passive buildings are buildings with low environmental impact [12].

After the 21 st century, the passive building certification system of various countries in the world began to be established, and related books appeared in endlessly. The content was mainly divided into: passive building case analysis, such as James Marley O'Connor's "Architecture and Passive Design", which showed some of the current Representative 
examples of passive energy-saving technologies [13]; passive building technologies, such as Manfred Hager's "Energy Atlas: Sustainable Buildings", which comprehensively introduces energy efficiency and sustainable buildings, which are substantial The practical value of [14]; passive building construction, such as "Passive Low Energy Buildings-Residential Buildings in Severe Cold and Cold Areas" published by China Building Standard Design and Research Institute, which lists the calculation formulas of passive building climate environment, energy consumption, and load, Provides detailed drawings of the nodes and construction requirements of various building envelopes and analyzes the performance indicators of the main building materials [15].

Nowadays, passive architecture shows the trend of localization and targeted research. The Macao Special Administrative Region is located in the south of Guangdong Province. It has a hot summer and warm winter climate. The land area is about 33 square kilometers. It has a dense population and scarce natural resources. It is highly dependent on imports in terms of raw materials, energy, and water resources. Therefore, it needs to use sustainable Technology, to alleviate the sense of crisis of natural resources by increasing revenue and reducing expenditure. In 2015, the China Green Building and Energy Conservation (Macao) Association published the "Green Building Evaluation Standards (Macau Version)", which provides a technical basis for green buildings in accordance with Macao's climate, environment, urban form, standard specifications, etc.[16]. In the same year, Emilio da Conceicao, a scholar at the Polytechnic Institute of Lisbon, wrote a dissertation "Sustainable Architecture in Macau: Green Casino", which analyzed the environmental performance of Macau architecture and established the theory of sustainable architecture and environmental comfort Framework, launched the direction of the study of sustainable architecture in Macao [17]. At present, the research on passive building technology in Macau is at the preliminary stage. Under the national call for carbon emission neutralization, passive building as a passive technology is of great significance to the development of sustainable buildings in Macau.

\section{The application strategy of passive architecture in Macau}

Passive architectural design in Macau should be suitable for the locality, taking into account Macau's local climate, resources, ecological environment, regional culture, economic level, existing buildings, policy regulations and other factors. Special attention is paid to the natural ecological environment of the building site, as Professor Song Dexuan's interpretation of energy-saving buildings: the development of buildings should not be transferred by human will, and the highest goal of naturalness, ecologicalization and environmental symbiosis should be pursued to use renewable energy in construction activities. The possibility is mainstream [18]. Therefore, in view of the special climatic conditions in Macau, specific issues of site planning, space and enclosure structure, heat collection and storage, ventilation and cooling, and shading need to be analyzed in detail.

\subsection{Macao's climate characteristics}

Macau is located about 140 kilometers south of the Tropic of Cancer. It belongs to a subtropical hot and humid climate zone. It is adjacent to Zhuhai City, Guangdong Province of the Asian continent to the north, and the South China Sea tropical ocean climate zone to the south. It is affected by the atmospheric circulation of the Asian continent in the middle and high latitudes and the ocean at low latitudes. Therefore, the summer and winter seasons are in a rainy climate zone (Table 1). 
Table 1. Macao 1981-2010 climate statistics (Macao Geophysical and Meteorological Bureau [19]).

\begin{tabular}{|c|c|c|c|c|c|c|c|}
\hline Month & $\begin{array}{c}\text { Average } \\
\text { temperature } \\
\left(\mathbf{}^{\circ} \mathbf{C}\right)\end{array}$ & $\begin{array}{c}\text { Relative } \\
\text { humidity } \\
(\mathbf{\%})\end{array}$ & $\begin{array}{c}\text { Sunshine } \\
\mathbf{t} \text { ime } \\
(\mathbf{h})\end{array}$ & $\begin{array}{c}\text { Total } \\
\text { rainfall } \\
(\mathbf{~ m m})\end{array}$ & $\begin{array}{c}\text { Wind } \\
\text { direction }\end{array}$ & $\begin{array}{c}\text { Wind } \\
\text { speed } \\
(\mathbf{k m} / \mathbf{h})\end{array}$ & $\begin{array}{c}\text { Thunderstorm } \\
\text { days }\end{array}$ \\
\hline 1 & 15.1 & 73.8 & 127.4 & 26.5 & $\mathrm{~N}$ & 14.1 & 0.1 \\
\hline 2 & 15.8 & 81.0 & 79.4 & 59.5 & $\mathrm{~N}$ & 13.3 & 0.7 \\
\hline 3 & 18.3 & 84.5 & 71.5 & 89.3 & $\mathrm{ESE}$ & 12.7 & 2.0 \\
\hline 4 & 22.1 & 86.1 & 85.3 & 195.2 & $\mathrm{ESE}$ & 12.6 & 3.8 \\
\hline 5 & 25.6 & 84.4 & 136.4 & 311.1 & $\mathrm{ESE}$ & 12.6 & 7.0 \\
\hline 6 & 27.6 & 84.0 & 155.3 & 363.8 & $\mathrm{~S}$ & 12.7 & 10.0 \\
\hline 7 & 28.6 & 81.8 & 223.2 & 297.4 & $\mathrm{SSW}$ & 12.4 & 9.0 \\
\hline 8 & 28.4 & 81.4 & 195.4 & 343.1 & $\mathrm{ESE}$ & 11.4 & 10.5 \\
\hline 9 & 27.4 & 77.9 & 176.5 & 219.5 & $\mathrm{ESE}$ & 13.1 & 6.5 \\
\hline 10 & 25.0 & 72.4 & 192.3 & 79.0 & $\mathrm{~N}$ & 14.5 & 0.9 \\
\hline 11 & 20.9 & 70.2 & 172.2 & 43.7 & $\mathrm{~N}$ & 15.1 & 0.1 \\
\hline 12 & 16.8 & 68.5 & 159.1 & 30.2 & $\mathrm{~N}$ & 14.8 & 0.1 \\
\hline
\end{tabular}

According to the statistics in Table 1, the spring and autumn seasons in Macao are relatively short. The cold winter air flow in spring meets the warm air flow in summer. In autumn, under the dominance of cold air, the winter monsoon of the northern East Asian continent replaces the summer monsoon, and the rainfall is reduced. The northerly wind is the most comfortable season of the year. In summer, the north-south wind from the west merges and moves northward. An anti-cyclone forms high above the Qinghai-Tibet Plateau. The south is a tropical easterly wind. Controlled by the easterly wind in South China, the subtropical high pressure increases significantly in the west. Therefore, the northeast monsoon is replaced by the southwest monsoon, and the south is affected by coastal airflow. In addition to the influence of the summer monsoon, a rainy and typhoon climate is formed, and it is in hot and rainy weather. In winter, affected by the subtropical westerly wind, the subtropical high-pressure air in the western Pacific is weak and stays in the south. At the same time, affected by the north-northeast airflow, cold winds from the south and strong cold winds from the north reach Macau, resulting in cold and dry weather. To sum up, due to its unique geographical location, Macao has formed its climate characteristics such as high temperature, high average wind speed, high relative humidity, and high rainfall.

\subsection{Site strategy}

Utilize and transform the terrain and climatic conditions of the site to create an external environment conducive to passive buildings. Under the climatic conditions of hot summer and warm winter in Macao, the building should have the functions of ventilation, shading and lighting to improve the comfort of the indoor space, and at the same time have a certain function of resisting natural disasters. The specific measures are as follows:

\subsection{Site disaster avoidance}

Macau is prone to frequent typhoons in summer and is prone to urban floods. Buildings should be avoided in low valleys or low-lying areas. They can be built on top of the terrain or built on high points, and plants with good grip should be planted to prevent soil erosion and landslides. As shown in the left and middle images of Figure 1. There is the Nossa da Penha de Frana Sanctuary on the high point of the Nossa da Penha de Frana mountain in Macau (picture 1 on the right). In addition to religious factors, the reason for the site selection is also to resist urban floods. 

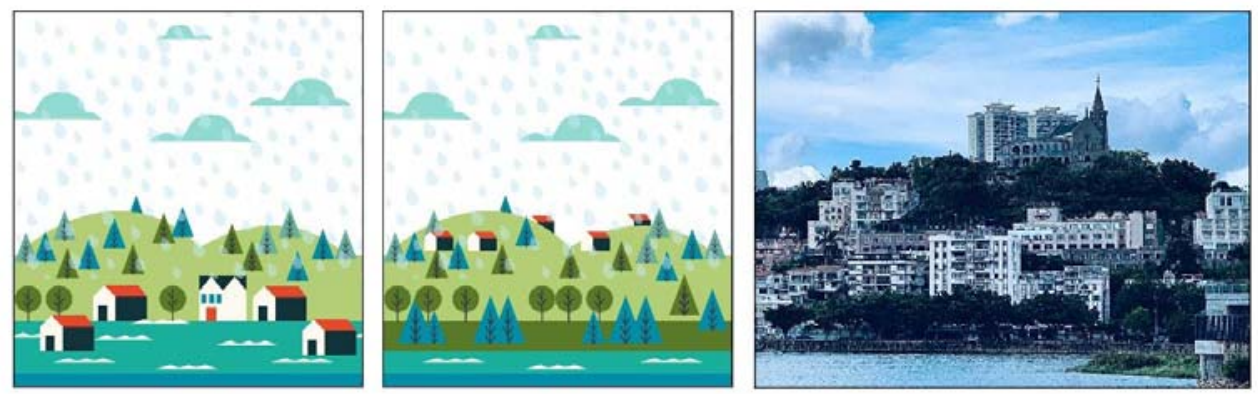

Fig. 1. The impact of rainfall on buildings in different locations on the mountain (self-painted).

\subsection{Venue shading}

Direct sunlight is the main cause of overheating inside the building. In order to avoid direct sunlight, the location of the building is very important. During the peak period of solar radiation, the left picture in Figure 2 is exposed to sunlight, which is not conducive to cooling and heat dissipation of the building. The building in the middle picture in Figure 2 is located on the shaded side of the mountain, which is more beneficial to the shading of the building. Picture 2 The right picture shows the Charity Association of Jinghu Hospital at the foot of Parque Municipalda Colinade Mong Há Mountain in Macau. It is located on the shady side of the mountain, effectively avoiding direct sunlight.
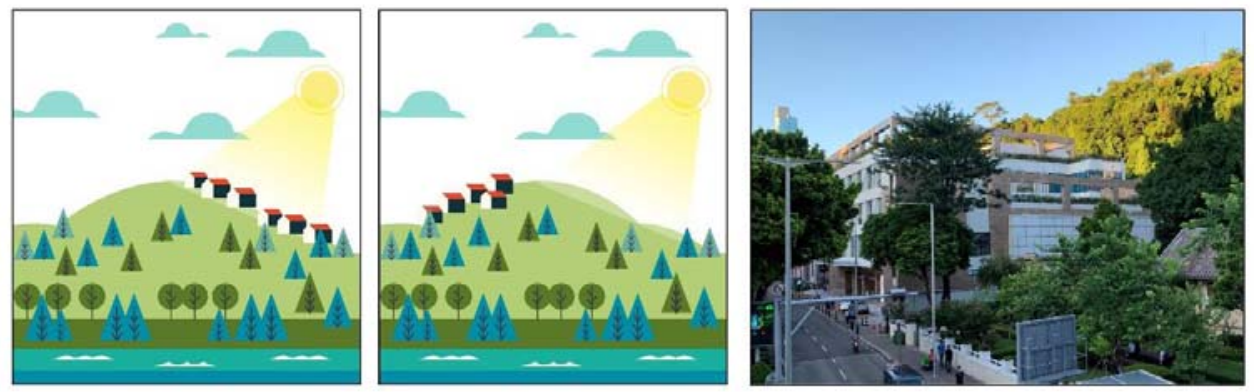

Fig. 2. The influence of the path of the sun on buildings at different locations on the mountain (selfpainted).

In the urban environment, not only will there be direct sunlight problems, the existing buildings in high-density residential areas will also refract sunlight, forming a microclimate, and intensifying the impact of sunlight on buildings and public spaces, as shown in the left picture of Figure 3. Therefore, it is necessary to change the building form and improve the public space environment. Sloping roofs can avoid the impact of sunlight refraction on the building, planting plants can inhibit sunlight, and use the transpiration effect of plants to promote air circulation and reduce air temperature. The picture on the right of Figure 3 shows the Macau Dashengwei. The sloped roof of the building reduces the impact of sunlight refraction on the surrounding buildings. 

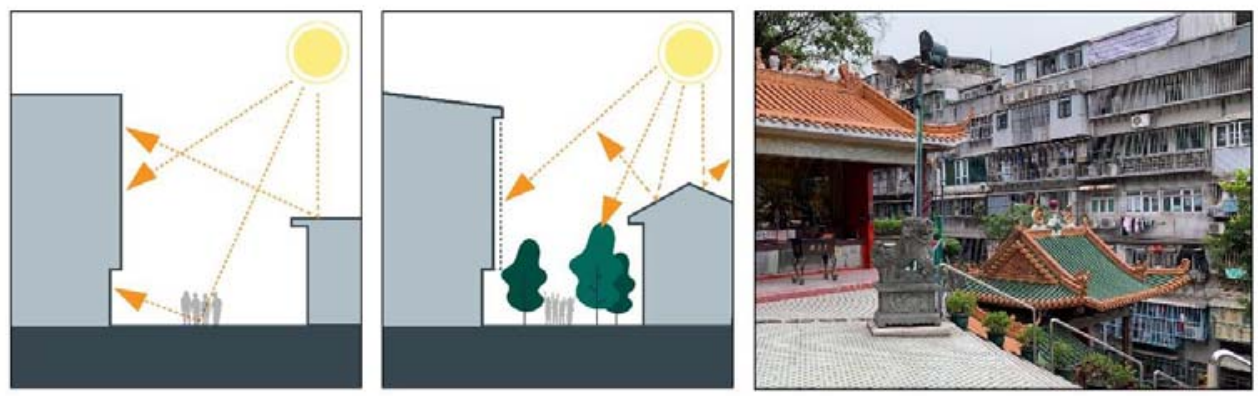

Fig. 3. The influence of plants and building forms on light (self-painted).

\subsection{Site ventilation}

The research on the wind environment of the site is beneficial to improve the ventilation of the building, thereby reducing the dependence on air-conditioning equipment, especially in the hot summer of Macau. The building on the left in Figure 4 is located on the leeward side of the mountain, which is not conducive to the natural ventilation of the building. The building in Figure 4 is located on the windward side of the mountain, which improves the efficiency of natural ventilation. The right picture of Figure 4 shows the western view of Yangshan in Macau. Based on field investigations, there are obvious differences in the ventilation volume of the buildings on the east and west sides.
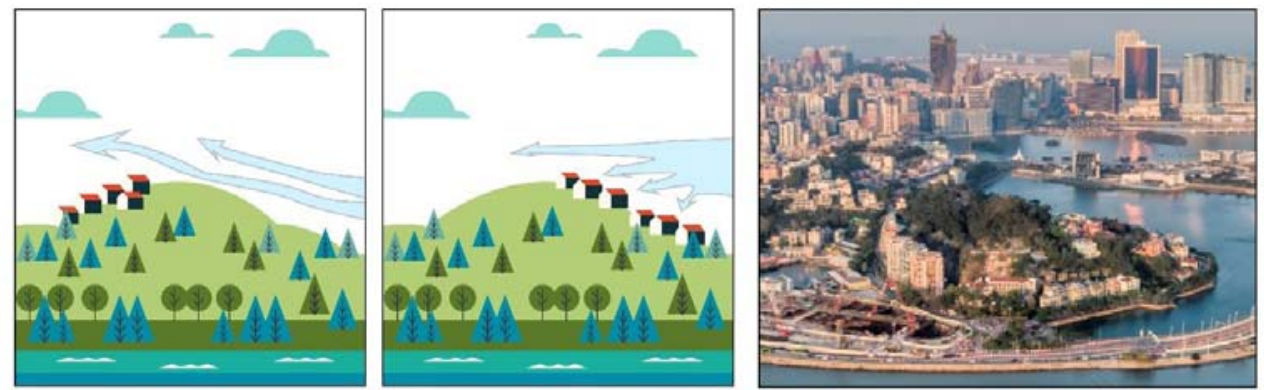

Fig. 4. The influence of wind on the hillside (self-painted).

The direction of the building and the dominant wind is also very important. The building group on the left of Figure 5 is perpendicular to the dominant wind direction, forming a wind barrier and obstructing the natural ventilation of the buildings behind it. The building level in the picture in Figure 5 is at the prevailing wind direction and has a good ventilation effect. The right picture in Figure 5 shows the Sao Paulo Street in Macau. The buildings on both sides of the street are at the prevailing wind direction and natural ventilation is good. 

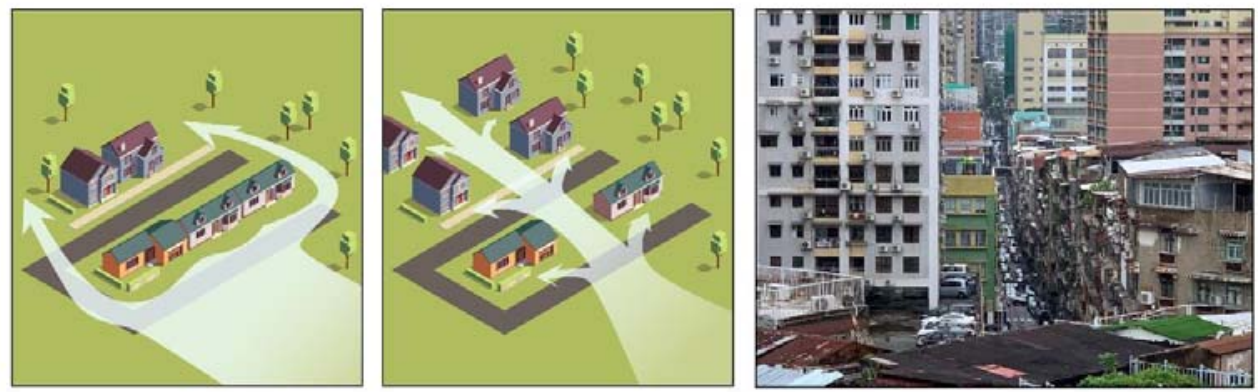

Fig. 5. The influence of building orientation and layout on natural ventilation (self-painted).

In addition, when high-rise buildings around the building block block the natural ventilation path, it will also cause poor ventilation, as shown in the left picture of Figure 6. Therefore, the location of high-rise buildings needs to be adjusted to make it more conducive to the natural ventilation of the building, as shown in the diagram in Figure 4. The right picture in Figure 6 shows the lower ring area of Macau. The high-rise buildings are located on the southwest side of the site to avoid obstruction to the ventilation path.
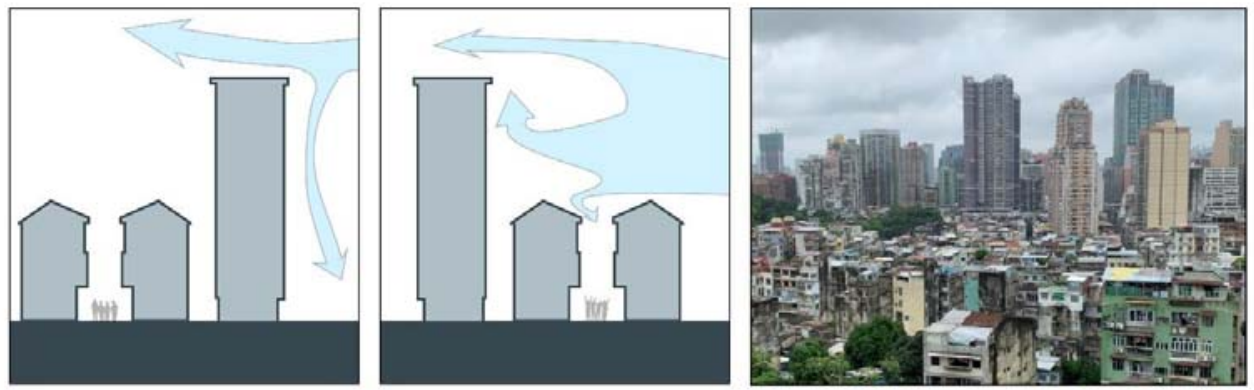

Fig. 6. The impact of high-rise buildings on natural ventilation (self-painted).

\subsection{Space and enclosure structure}

Due to the difference in the azimuth of the building, the solar radiation received is not the same. When the azimuth of the heat collection is too large, the solar radiation will be reduced, which will directly affect the natural lighting of the building. Therefore, in order to receive as much solar radiation as possible, it should be Orient the building to the south side. Through the software simulation of Autodesk Ecotect, it is calculated that the best orientation of the building is $7.5^{\circ}$ from due south to east, as shown in Figure 7. In addition, in the "Technical Specification for Passive Solar Buildings", it is recommended that the building orientation should be controlled within the range of $15^{\circ}$ from the south to the east or west. Exceeding this range will affect the effect of solar heating in winter and easily lead to overheating of indoor air temperature in other seasons[5]. 


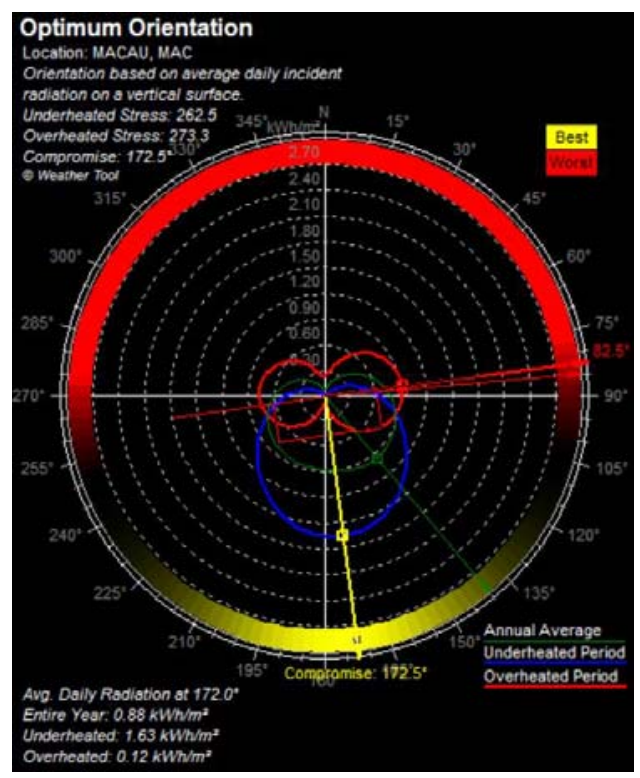

Fig. 7. The best sun direction in Macau (simulation diagram of Autodesk Ecotect software).

Opening the openings of doors and windows is conducive to organizing wind through the hall, increasing natural ventilation, preserving smooth air circulation and improving air quality. For example, in the Zheng Family House in Macau, the inlet and outlet windows are opposite to form good air convection. At the same time, there are shutters and shutters. Architectural components such as Liangzi have the effect of shading while ventilating, as shown in Figure 8. In addition, reasonable adjustment of the size of the indoor air inlet and outlet of the building is beneficial to adjust the air flow rate. When the building is located in the dominant wind direction, the area of the air inlet is larger than the air outlet area, which is beneficial to increase the air flow rate and improve air quality.

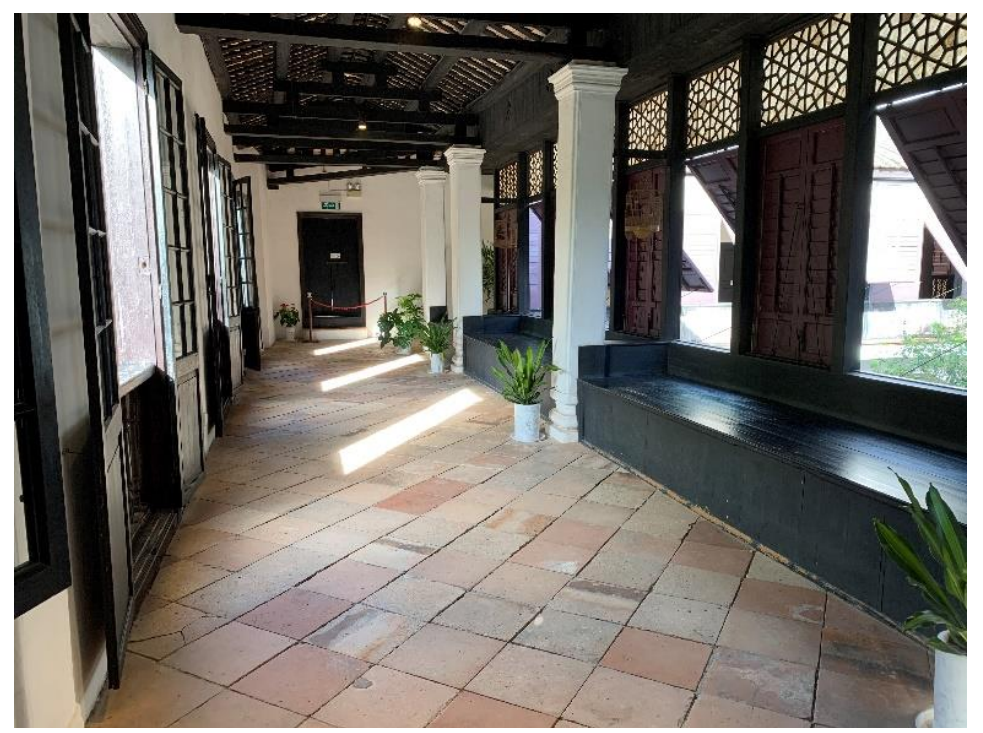

Fig. 8. The corridor on the second floor of the Zheng's House in Macau (self-photo). 


\subsection{Ventilation, cooling and shading}

Most of the traditional residences of Lingnan in Macao are equipped with natural ventilation measures such as patios and atriums, as shown in Figure 9. Solar radiation enters the building interior through the patio, making the air in the building higher than the outdoor air temperature. As the air temperature rises and the density is reduced, the heat pressure is used to form a chimney effect and achieve the effect of passive ventilation and cooling.

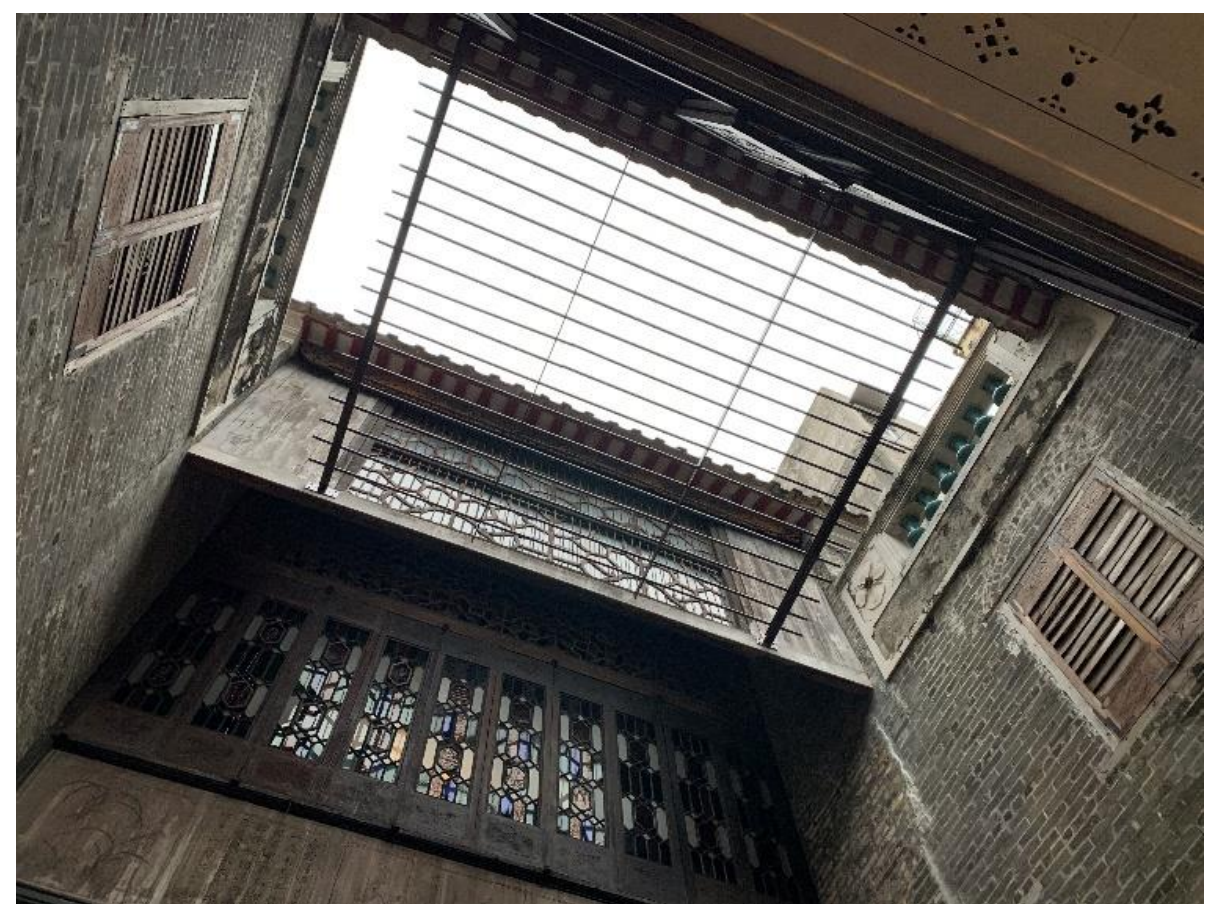

Fig. 9. The patio of Lu's House in Macau (self-photo).

Venetian blinds are often used as external shading components for traditional buildings in Macau, whether Western or Chinese, as shown in Figure 10. As a kind of horizontal component, it is not only easier to install than vertical, lattice and surface type, but also will not cause major obstacles to receiving solar radiation in winter. The flexible louver is conducive to adjusting the angle of sunshade to achieve the best Good shading effect. 


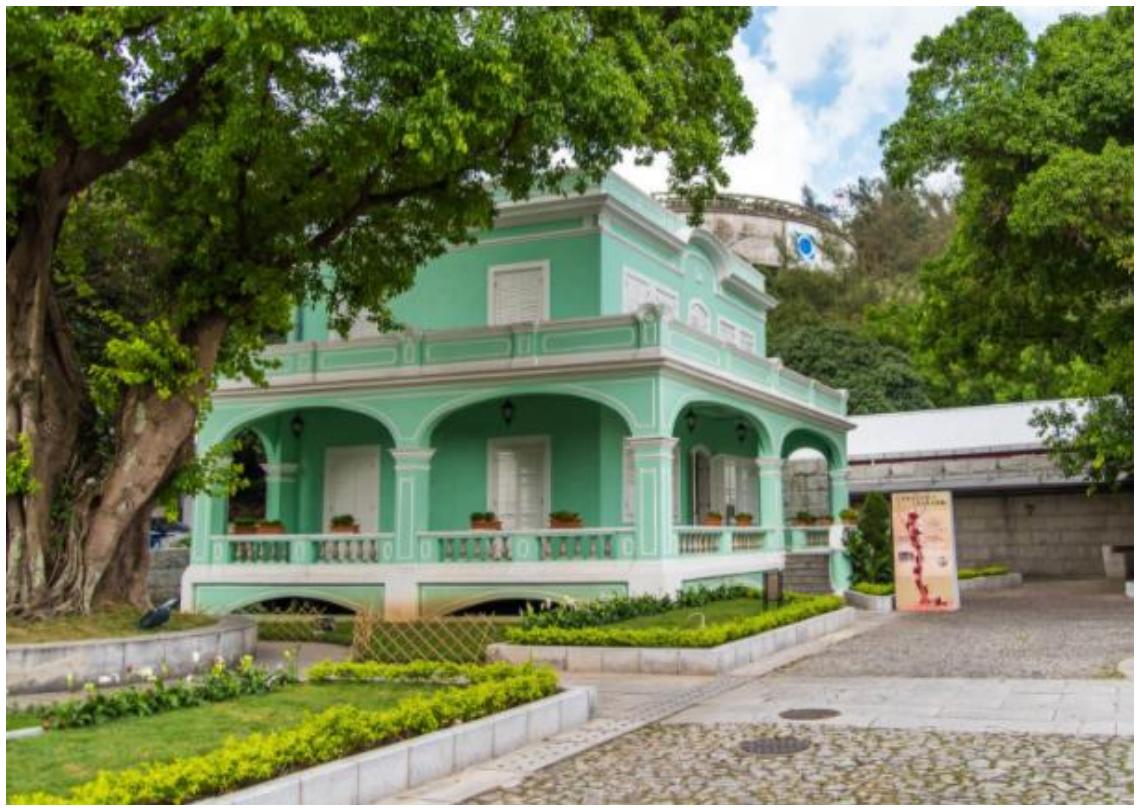

Fig. 10. Macau Taipa Portuguese residential diagram (self-photo).

The light-colored walls will reflect most of the solar radiation, reduce the heat conduction of the wall, thereby reducing the indoor temperature. For example, most of the residential buildings in Clinwei, Macau are installed with reflective metal materials on the walls of the building to prevent heat from being transmitted to the interior of the building. At the same time, it also has the function of strengthening the walls to prevent hot air from penetrating into the walls and rainwater from penetrating, and avoiding humid air on the walls. Condensate is formed.

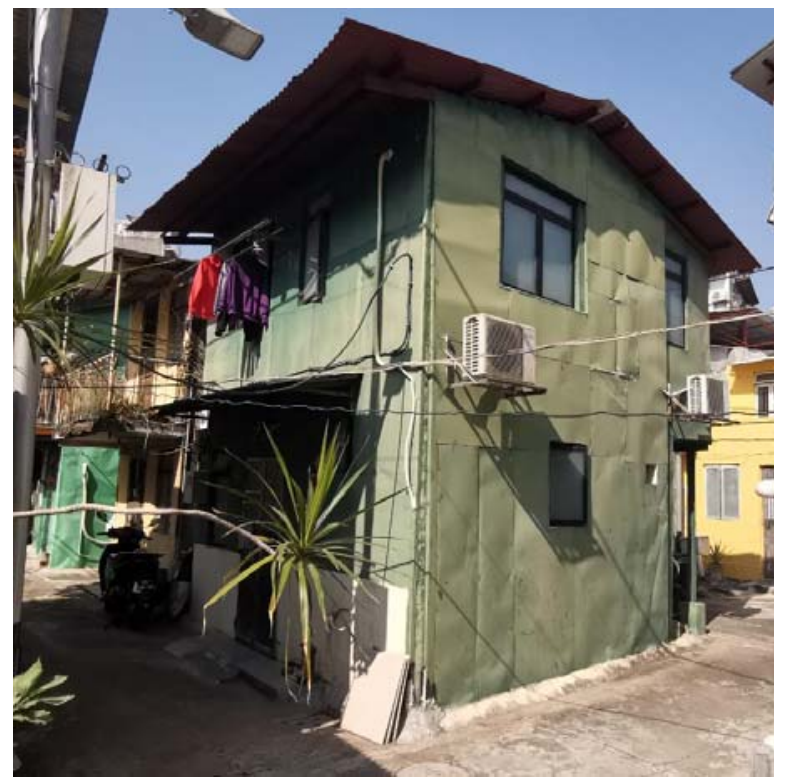

Fig. 11. Residential buildings in Cilinwei, Macau (self-photo). 


\section{Case analysis}

Macau has gone through the Portuguese colonial period for about 400 years. Therefore, many traditional Portuguese-style buildings have been built and have been well preserved. Traditional buildings have adopted different passive building technologies in response to the local climate, so that the buildings meet human health and basic Comfort. Nowadays, with the vigorous development of the tourism industry in Macau, a large number of advanced modern buildings have been built, both of which are remarkable in terms of architectural form and construction technology. This chapter gives examples of the passive construction technology used in traditional and modern buildings in Macau, and analyzes the differences in the architectural application of passive buildings in different periods.

\subsection{Traditional Portuguese architecture in Macau}

The Macao Jao Tsung-I Academy of Arts was built in 1921, located at 95 Avenida da Avenida Ferilila, Macau. It has a neoclassical architectural style and was originally a residential residence. The Macao Special Administrative Region Government commends Professor Jao Tsong-I's outstanding contribution to the academic research of Macao's literature and history. , Named it Macau Jao Tsung-yi Academy of Arts, built in, mainly used as a display of Professor Jao's works, as shown in Figure 12.

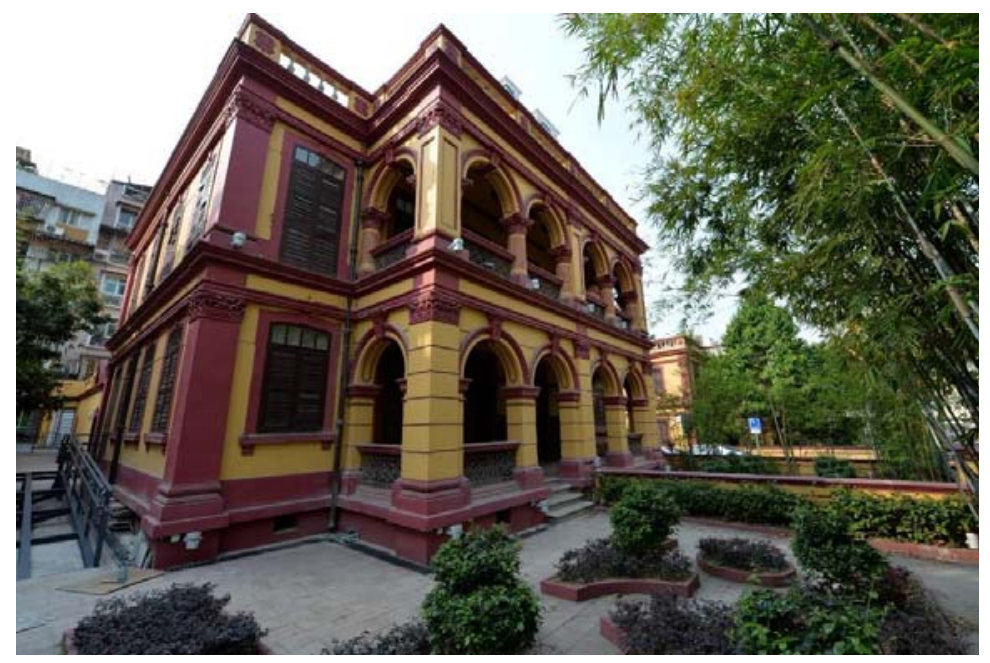

Fig. 12. Jao Tsung-I Academy of Arts in Macau (self-photo).

The Jao Tsung-I Academy in Macau has a width of about 14 meters, a depth of about 20 meters, and a height of about 11.8 meters. It has two floors. There are outer corridors on the upper and lower floors, the style is Western classical arches, the roof of the door has a red lock stone strengthening structure, and the outer corridor has the function of shading and raining. The foundation is elevated with ventilation holes, which indirectly reduces the indoor temperature through the transpiration of surrounding plants, as shown in Figure 13. The windows are casement shutters, which have a good shading effect, and the upper edges of the windows have bright lights, which are conducive to lighting. There are flower pattern holes in the ceiling of the second floor, which is good for ventilation, conducts indoor heat source and prevents termites. The roof is a double-slope tile roof, with a double-tube double-tile structure, which is insulated by airflow. 


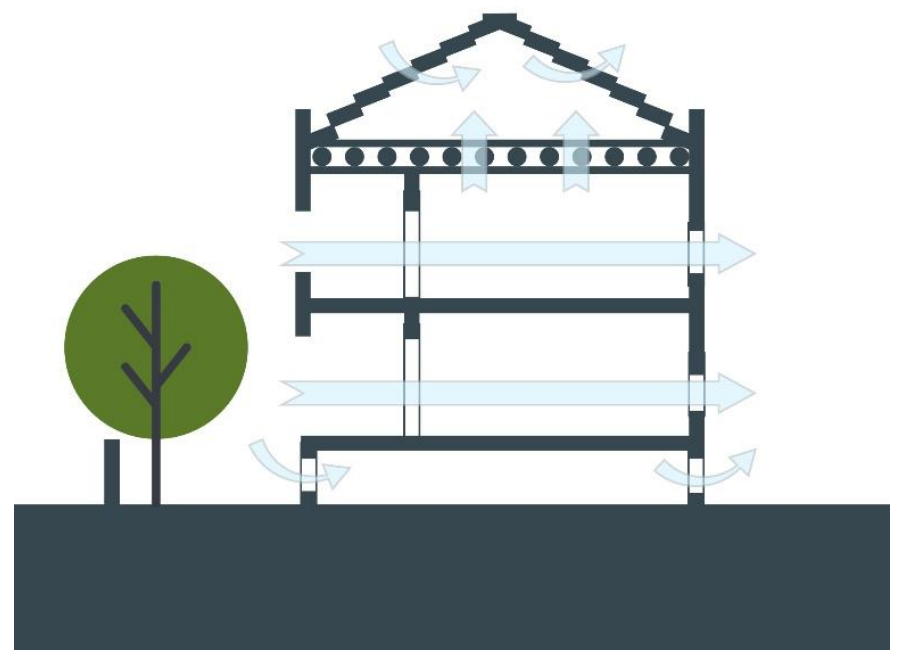

Fig. 13. Ventilation design of Jao Tsung-I Academy in Macau (self-painted).

\subsection{Modern public buildings in Macau}

The Student Activity Center of the University of Macau on Hengqin Island was built in 2014. It is located on Avenida da Avenida de Macau (University of Macau Hengqin Campus, Zhuhai City). It is a modern building that organizes various activities for students. It is also Macau's first green three-star certification Construction project. The building mainly adopts the design of shading and greening to realize the cooling and heat insulation of the building, and enhance the passive lighting and ventilation by optimizing the building space and form [20].

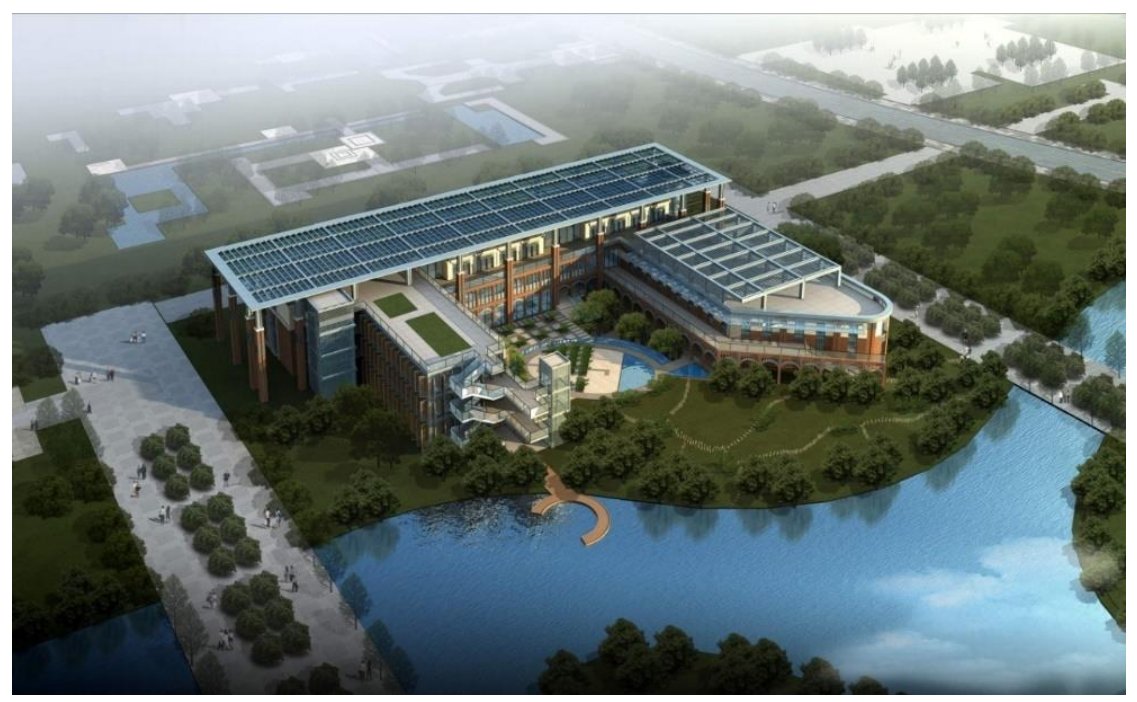

Fig. 14. University of Macau Student Center (provided by Guangzhou Songlin Construction Technology Co., Ltd. [21]).

The shape of the building adopts a "U" shape, and the opening of the form faces the lake to the north, and the microclimate of the lake is used to improve the environment. There are 
skylights on the roof to introduce solar radiation into the room, and use the principle of heat pressure to form a chimney effect to enhance natural ventilation. The openable area of the windows is about $30 \%$, the opening faces the dominant wind direction in summer, and the indoor space layout is reasonable, which is conducive to the formation of draughts. The organization of the outdoor wind environment considers the overall cluster layout of the campus, and forms air ducts by designing the building spacing. The first floor adopts an overhead method and uses the angle between the building orientation and the summer wind to promote ventilation. Through the combination of roof greening, vertical greening, courtyard greening and other greening measures, the outdoor thermal environment is improved and the landscape quality is improved. Use roof truss shading, veranda shading, horizontal shading and other shading methods to avoid excessive solar radiation. The windows are insulated with Low-E double-layer hollow glass, and shutters are used as external shading components to flexibly coordinate the balance of shading and daylighting.

\section{Conclusions and suggestions}

Passive building technology has existed since ancient times. With the popularization of modern and convenient facilities and equipment, the public once ignored passive energysaving measures. However, as the supply of non-renewable energy and global warming problems have emerged, the public is gradually facing environmental and energy-saving problems. Pay attention to it, and at the same time, under the national call for carbon neutrality, passive building technology has ushered in opportunities for popularization and development.

At present, there are few applications of passive construction technology in modern buildings in Macau. However, Macau has local energy shortages and over-reliance on imports. At the same time, as a world tourism center, a green tourism city has become the international mainstream trend. Passive building technology has mature With the accumulation of technology and a variety of international certification indicators, the use of passive building technology can not only reduce the dependence on energy, but also help achieve the national goal of carbon neutrality and build a brand of green tourism city. Therefore, it is urgent to start the localization of passive buildings. Research, comprehensively popularize passive building technology, combine Macau's special climate characteristics and cultural customs, use Macau's international platform, try a variety of new passive building materials and technologies, further optimize architectural design and construction, and promote the construction of Macau's green tourist city .

\section{References}

1. https://www.phius.org/home-page

2. https://passivehouse.com/

3. Publicly funded research group (Forum for Energy Efficient Buildings (FEBY), 2007)

4. http://www.jcadr.or.jp/

5. Ministry of Housing and Urban-Rural Development of the People's Republic of China, Technical specifications for passive solar buildings (China Construction Industry Press, Beijing, 2012)

6. M.H.M. Vitruvius, Vitruvius: The Ten Books on Architecture (Dover Publications, NYC, 1960)

7. The Orientation of Buildings. Joint Committee on the Orientation of Buildings Tapa dura (Royal Institute of British Architects, 1932) 
8. Reyner Banham, The Architecture of the Well-Tempered Environment (The University of Chicago Press, Chicago, 1960)

9. Givoni B. Man, Climate \& Architecture (Applied Science Publishers, London, 1976)

10. M. DeKay, G.Z. Brown, Sun, Wind, and Light: Architectural Design Strategies (Wiley, Hoboken, 1987)

11. G.Z. Brown, B. Haglund, J. Loveland, J.S. Reynolds, M. Susan Ubbelohde, Insideout: Design Procedures for Passive Environmental Technologies (Wiley, Hoboken, 1992)

12. K. Yeang, Designing With Nature: The Ecological Basis for Architectural Design (McGraw-Hill, NYC, 1995)

13. J.M. O'connor, Architecture \& Passive Design (Design Media Publishing Ltd., London, 2015)

14. M. Hegger, M. Fuchs, T. Stark, M. Zeumer, Energie Atlas: Nachhaltige Architektu (Birkhäuser, Basel, 2007)

15. China Building Standard Design and Research Institute, Passive low-energy buildingsresidential buildings in severe cold and cold areas (China Planning Press, Beijing, 2017)

16. http://www.chinagbc-macau.org/file/standard.pdf

17. E. Alfredo da Conceição, Sustainable Architecture in Macau: The Green Casino (Universida de Técnicade Lisboa, Lisboa, 2015)

18. Song Dexuan, Energy-saving building design and technology (Tongji University Press, Shanghai, 2002)

19. https://www.smg.gov.mo/zh/subpage/348/page/252

20. Huang Jun, Lin Yan, Wang Shixiao, Journal of South China University of Technology (Natural Science Edition) 44(7) (2016)

21. http://songlinjk.com/page12?product_id $=183$ 